\title{
Design and Implementation of High Frequency Buck Converter Using Multi-Layer PCB
} Inductor

Nour, Yasser; Ouyang, Ziwei; Knott, Arnold; Jørgensen, Ivan Harald Holger

Published in:

Proceedings of the 42nd Annual Conference of IEEE Industrial Electronics Society

Link to article, DOI:

10.1109/IECON.2016.7794148

Publication date:

2016

Document Version

Peer reviewed version

Link back to DTU Orbit

Citation (APA):

Nour, Y., Ouyang, Z., Knott, A., \& Jørgensen, I. H. H. (2016). Design and Implementation of High Frequency

Buck Converter Using Multi-Layer PCB Inductor. In Proceedings of the 42nd Annual Conference of IEEE Industrial Electronics Society (pp. 1313-1317). IEEE. https://doi.org/10.1109/IECON.2016.7794148

\section{General rights}

Copyright and moral rights for the publications made accessible in the public portal are retained by the authors and/or other copyright owners and it is a condition of accessing publications that users recognise and abide by the legal requirements associated with these rights.

- Users may download and print one copy of any publication from the public portal for the purpose of private study or research.

- You may not further distribute the material or use it for any profit-making activity or commercial gain

- You may freely distribute the URL identifying the publication in the public portal 


\title{
Design and Implementation of High Frequency Buck Converter Using Multi-Layer PCB Inductor
}

\author{
Yasser Nour, Ziwei Ouyang, Arnold Knott, Ivan H. H. Jørgensen \\ Department of Electrical Engineering, Technical University of Denmark \\ Elektrovej, Building 325 \\ 2800 Kongens Lyngby, Denmark \\ \{ynour, zo, akn,ihhj\}@elektro.dtu.dk
}

\begin{abstract}
Increasing the switching frequency for switch mode power supplies is one of methods to achieve smaller, lighter weight and cheaper power converters. This work investigates the opportunity of using two layer circular spiral inductors implemented in a $150 \mu \mathrm{m}$ finished thickness printed circuit board for a high frequency DC-DC converter. The inductor was tested in a $5 \mathrm{~W}$ buck converter switching at $10 \mathrm{MHz}$. The converter achieved $84.7 \%$ peak efficiency converting $12 \mathrm{~V}$ to $5 \mathrm{~V}$ and $78 \%$ efficiency converting $24 \mathrm{~V}$ to $5 \mathrm{~V}$.
\end{abstract}

Keywords - PCB Inductors, Gallium Nitride, High Frequency Converters

\section{INTRODUCTION}

From the early beginning of using switch mode power supplies, it was obvious that the higher the switching frequency, the smaller the converters will be. Efficiency and thermal penalties were the limiting parameters for pushing the switching frequency to higher values. To develop such small power converters new semiconductor materials, innovative packaging, high frequency $(300 \mathrm{KHz}-30 \mathrm{MHz})$ magnetics and development of converter topologies are the pillars for achieving efficient power conversion. It was clear that silicon switches have a lot of limitations when used in high switching frequency converters especially at elevated input voltages. Gallium nitride $(\mathrm{GaN})$ based converters have shown a boost in converter efficiencies due to their lower parasitic capacitances and improved figure of merits $[1,2]$

For the magnetic components, air core inductors are often being used in high frequency and very high frequency converters. Printed circuit board (PCB) planar air core inductors can be used as antenna or components for composing high-frequency matched filters in a Radio-frequency identification (RFID) system [3]. Recently, power supply on chip has gained their popularity and integrated air core inductors are often employed within very high frequency to achieve a higher power density [4-7]. PCB air core inductors do not need space to accommodate the magnetic core and have no core limitations such as core losses and saturation. Therefore, the size of PCB air core inductors can be significantly smaller, making it well suitable for applications that have stringent space and height requirements. The inductor windings manufactured by PCB machines are more precise and consistent, yielding the inductor designs with highly controllable and predictable parasitic parameters [8].

The frequency dependence of a PCB inductor must be considered under higher frequency. The eddy current effect at high frequencies dramatically increases effective resistance of a multi-turn spiral inductor winding. Current crowding is studied through approximate analytical modeling in [9].The nonuniform current distribution on the metallic trace is studied based on conventional magnetic flux method and energy method in [10]. Hurley et al. [11], presents a precise impedance formula with consideration of non-uniform current distribution and lossy magnetic media. Electromagnetic interference (EMI) is of particular concern in the PCB air core inductor working under multi-megahertz power converters. Unwanted stray magnetic fields can readily couple to near-by structures. It is well known that the addition of magnetics core plates to either side of the PCB winding provides enhancement of inductance values, and reduction of EMI problem. This paper focuses on the design and testing of a printed circuit board based inductor suitable for high switching frequency applications.

\section{CONVERTER Design}

To test the inductors, a soft switching buck converter was chosen as it is the most basic step down switching converter. Zero-Voltage-Switching Quasi-Square-Wave (ZVS-QSW) was used as a switching technique. This switching technique uses the inductor current to charge or discharge the output capacitance of a semiconductor switches; resulting in much lower output capacitance related switching losses with a slightly higher conduction loss $[1,12,13]$.Compared to hard switching buck converter, the total losses should be maintained lower by proper design. The detailed operation of ZVS-QSW buck converter was reported in [1]. Simple ZVS- QSW buck converter and the loaded converter's ideal waveforms are shown in Figure.1. The inductor value needed for a ZVS- QSW buck has to be less than the inductor value needed to operate a buck converter in critical conduction mode which is given by Equation.1 [14].

$$
L_{O(\min )}=\frac{(1-D)}{2 F_{S W}} R_{L o a d}
$$


For QSW-ZVS operation, it is important to assure the inductor current has the needed negative valley value based on equation.2 [14].

$I_{L o \text { (min) }}=I_{\text {Load }}-\frac{\Delta I_{L o}}{2}=\frac{V_{O}}{R_{\text {Load }}}-\frac{V_{O}}{2 L_{O} F_{S W}}(1-D)$

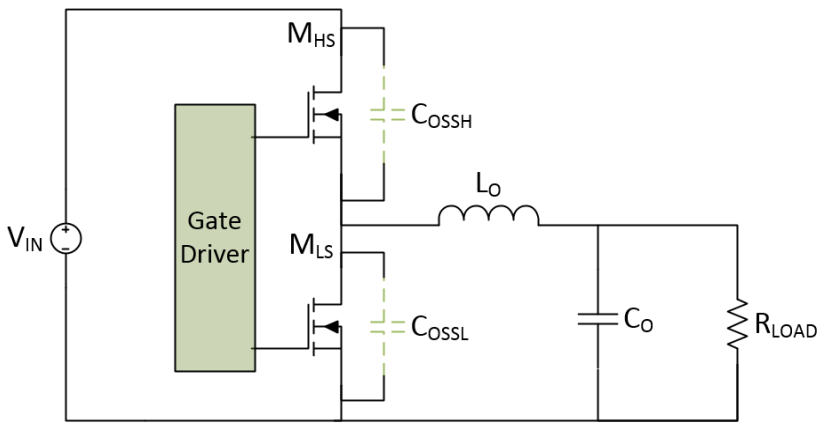

a. Power stage schematic.

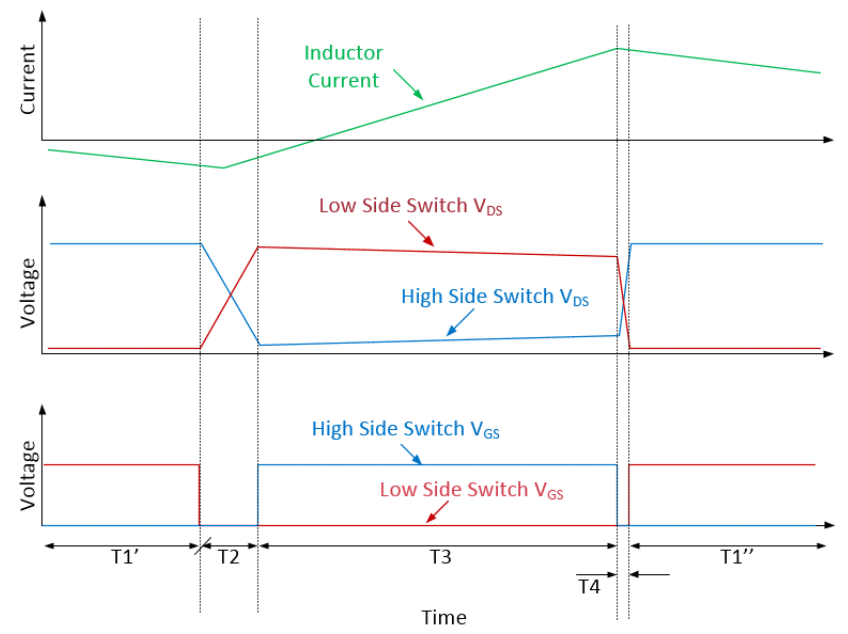

b. Converter waveforms with load.

Fig. 1. Simplified QSW-ZVS Buck Converter [1]

Accurate gate drive timing is needed to achieve zero voltage switching and also to reduce the power loss in body diodes or power loss due to reverse conduction charge $[14,15]$. The converter specifications are summarized in table 1 . The critical inductance value needed is summarized in figure 2 . To simplify the test procedure, the switching frequency was kept constant. This means the converter will be operating in hard switching during heavy load values and low input voltages.

TABLE. 1 TEST CONVERTER SPECIFICATIONS

\begin{tabular}{l|l||l} 
Parameter & Value & Description \\
\hline \hline $\mathrm{V}_{\text {IN }}$ & $24 \mathrm{~V}$ & Input Voltage \\
\hline $\mathrm{V}_{\text {OUT }}$ & $5 \mathrm{~V}$ & Output Voltage \\
\hline $\mathrm{I}_{\text {OUT }}(\mathrm{Max})$ & $1 \mathrm{~A}$ & Maximum Output Current \\
\hline $\mathrm{F}_{\mathrm{SW}}$ & $10 \mathrm{MHz}$ & Switching Frequency \\
\hline \hline
\end{tabular}

Switching at such high frequencies, it is required to choose high speed switches with low gate losses. The output capacitance related losses are minimized by the soft switching. A study was made in [1] comparing the figure of merits (FOMs) for both GaN FETs and silicon MOSFETs at different ratings of drain to source voltage. The results of that study are shown in figure 3 and figure 4 which clearly show the superiority of GaN FETs at all voltage levels. Two EPC8010 eGaN devices were chosen to carry out the design of the test converter for the inductors [16].

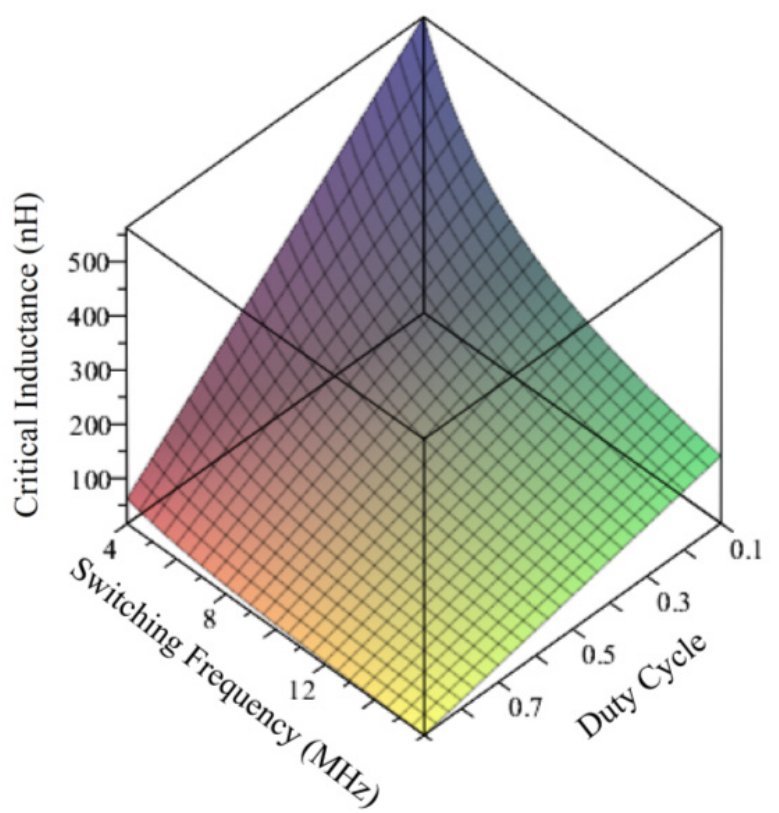

Fig. 2. Ideal critical inductance as a function of the switching frequency and duty cycle at $5 \mathrm{~V}$ output voltage and $1 \mathrm{~A}$ output current.

\section{MODELLING AND FEA SimULATIONS OF PCB INDUCTOR}

For $\mathrm{N}_{\mathrm{p}}$ turns spiral primary winding, the total selfinductance of the primary winding is the summation of each mutual inductance pairs between two concentric winding tracks, $\mathrm{M}_{\mathrm{ij}}$, where both $\mathrm{i}$ and $\mathrm{j}$ are from 1 to $\mathrm{N}_{\mathrm{p}}$. The selfinductance of the primary winding is given by Equation 3 .

$$
L_{p}=\sum_{j=1}^{N_{p}} \sum_{i=1}^{N_{p}} M_{i j}
$$

Figure 4 shows a generic cross-section of a PCB coreless inductor along 2-D X-Z plane. In practice a spiral arrangement would connect two layer sections in series, which can be accurately modelled by the concentric circular coils. Derivation of the mutual inductance, $\mathrm{M}_{\mathrm{ij}}$, in a PCB coreless inductor was proposed by Hurly $[11,17]$ and is given by equation 4 .

The formulas have been derived from Maxwell's equations and therefore they can be fully expected to represent practical planar devices accurately. The extension of the formula can also cover the cases that the addition of magnetics core plates to either side of PCB winding structures. 


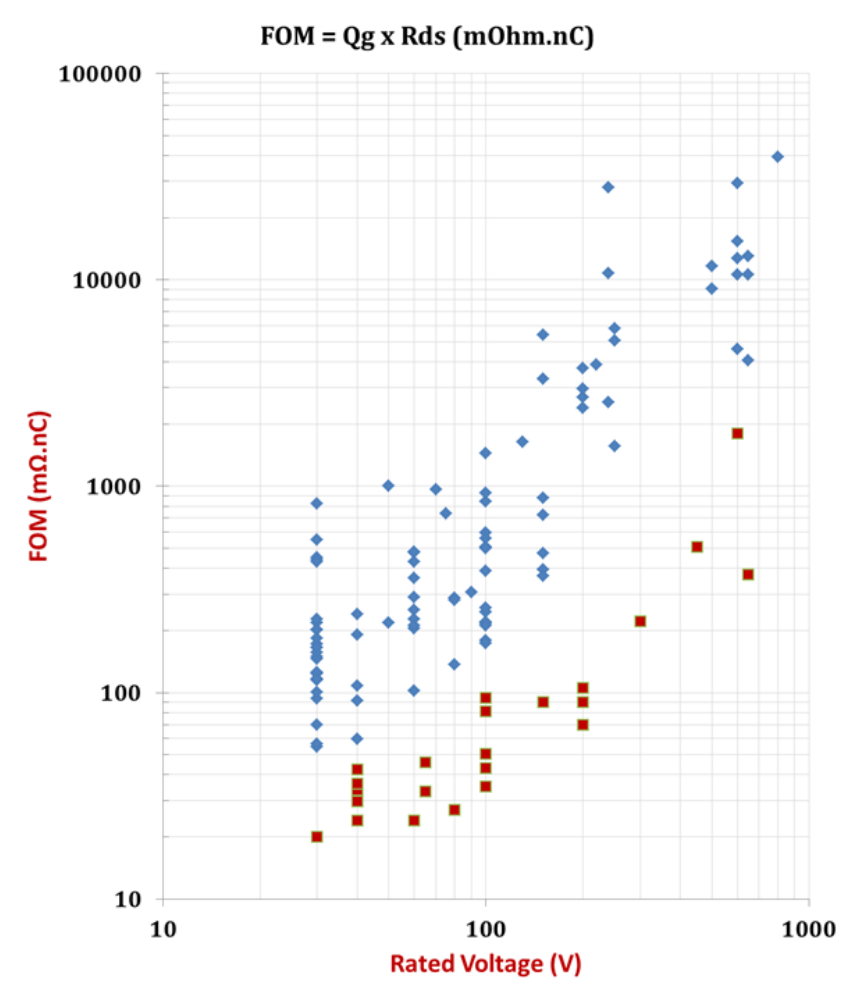

- Si MOSFETs - Discrete - GaN FETs - Discrete

a. Summary of high voltage FETs $Q_{g \text { tot }} \cdot R_{\mathrm{ON}}$

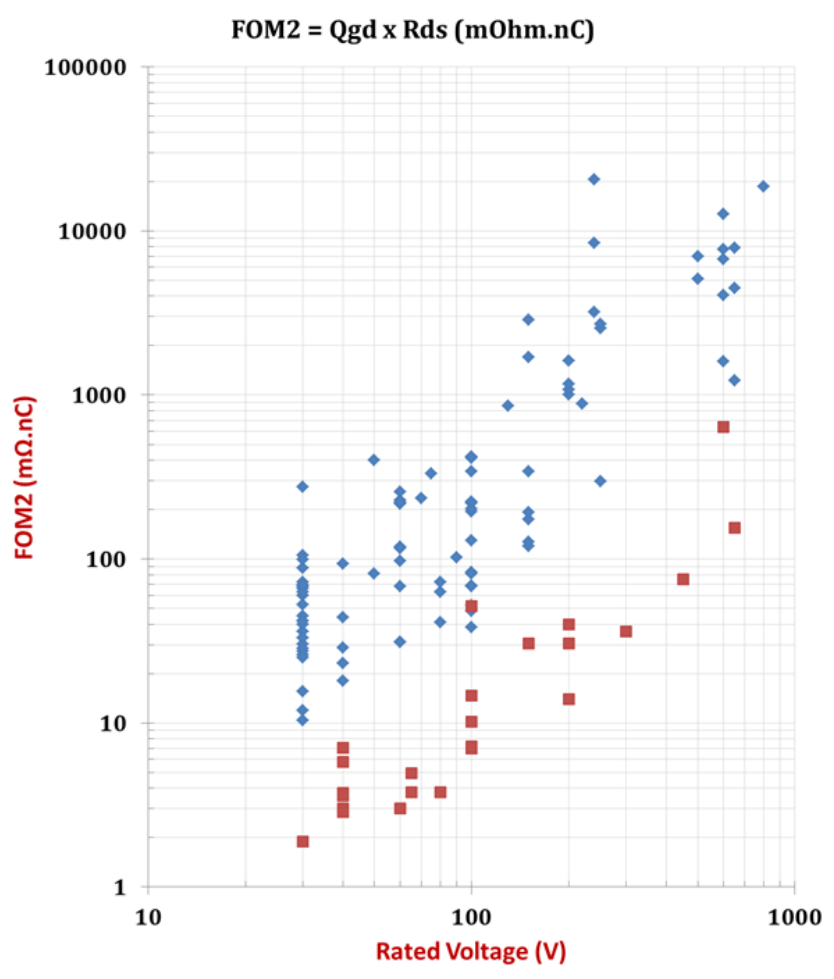

- Sillicon MOSFETs - Discrete $\quad$ GaN FETs - Discrete

b. Summary of high voltage FETs $Q_{g d}$. $R_{O N}$

Fig. 3. Summary of gallium nitride vs. silicon FETs figure of merits [1]

$$
\begin{gathered}
M_{i j}=\frac{\mu_{0} \cdot \pi}{h_{1} \cdot h_{2} \cdot \operatorname{In}\left(\frac{r_{2}}{r_{1}}\right) \cdot \operatorname{In}\left(\frac{a_{2}}{a_{1}}\right)} \cdot \int_{0}^{\infty} S\left(k r_{2}, k r_{1}\right) \cdot S\left(k a_{2}, k a_{1}\right) \cdot e^{-k \cdot z} \\
\cdot Q\left(k h_{1}, k h_{2}\right) \cdot d k
\end{gathered}
$$

where

$$
\begin{aligned}
& S\left(k r_{2}, k r_{1}\right)=\frac{J_{0}\left(k r_{2}\right)-J_{0}\left(k r_{1}\right)}{k} ; \\
& S\left(k a_{2}, k a_{1}\right)=\frac{J_{0}\left(k a_{2}\right)-J_{0}\left(k a_{1}\right)}{k} ; \\
& Q\left(k h_{1}, k h_{2}\right) \\
& =\left\{\begin{array}{c}
\frac{2}{k^{2}}\left(\cosh k \cdot \frac{h_{1}+h_{2}}{2}-\cosh k \cdot \frac{h_{1}-h_{2}}{2}\right), \text { when } z>\frac{h_{1}+h_{2}}{2} \\
\frac{2}{k} \cdot\left(h-\frac{e^{-k h}-1}{k}\right), \text { when } z=0, h_{1}-h_{2}=h
\end{array}\right. \\
& \mu 0 \quad \text { is permeability of airgap; } \\
& \text { h1 is the height of the ith circular track; } \\
& \text { h2 is the height of the } j^{\text {th }} \text { circular track; } \\
& r 1, r 2 \text { are the inner and outer radius of } j^{\text {th }} \text { circular track; } \\
& \text { a1, a2 are the inner and outer radius of } i^{\text {th }} \text { circular track; } \\
& J 0(x) \quad \text { is first kind Bessel function of order zero; }
\end{aligned}
$$

The model then was imported to Ansys Maxwell software for simulation and series resistance extraction. Figure 5 shows different views of the designed inductor and the design parameters are shown in table 2 .

TABLE. 2. DESIGNED INDUCTOR PARAMETERS

\begin{tabular}{l|l} 
Parameter & Value \\
\hline \hline $\mathrm{h} 1 \& \mathrm{~h} 2$ & $35 \mu \mathrm{m}$ \\
\hline $\mathrm{z}$ & $80 \mu \mathrm{m}$ \\
\hline Track width & $1 \mathrm{~mm}$ \\
\hline Track clearance & $300 \mu \mathrm{m}$ \\
\hline Inner coil radius & $1.5 \mathrm{~mm}$ \\
\hline PCB size & $12 \mathrm{~mm} \times 12 \mathrm{~mm}$ \\
\hline \hline
\end{tabular}

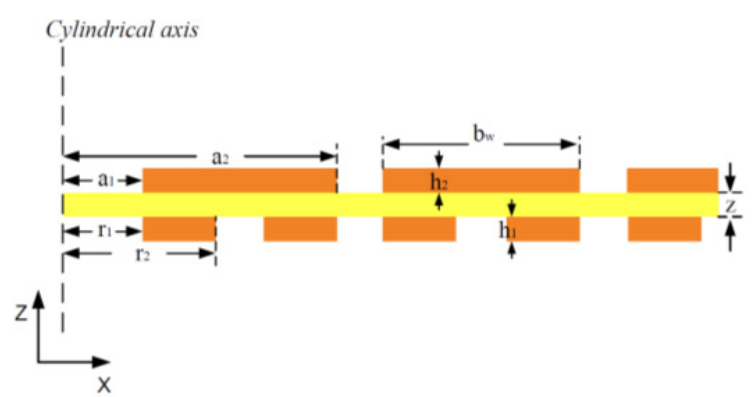

Fig. 4. A generic cross-section of a PCB inductor 
Figure 6 shows FEA simulation of the current density $(\mathrm{J})$ at $10 \mathrm{MHz}$ using Ansys Maxwell. It is obvious from the figure that the current is pushed to the vertical edges of the spiral which impacts the AC resistance of the inductor.

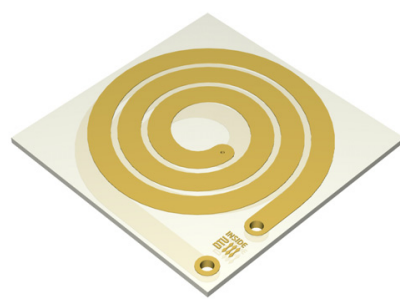

3D View

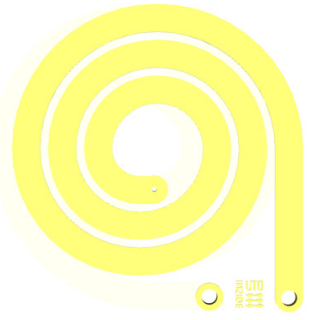

Bottom View

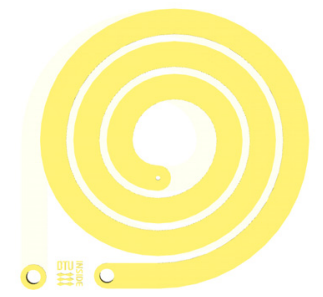

Top View

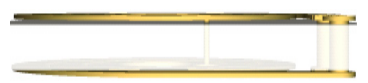

Side View
Fig.5. Two layer Ring Spiral Inductor
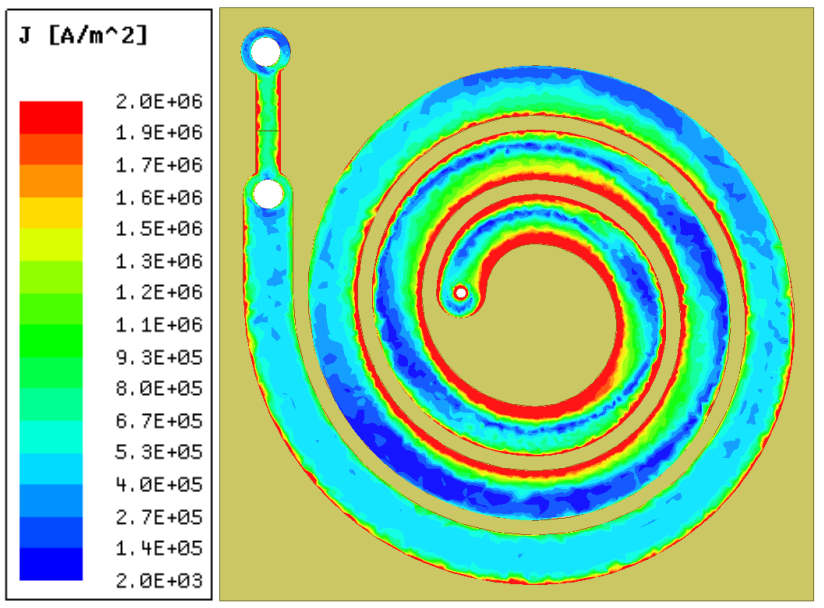

Fig.6. The current density at $10 \mathrm{MHz}$ (top view)

\section{EXPERIMENTAL RESULTS}

The two layer inductor prototype was manufactured and measured using an Agilent 4294A precision impedance analyzer. The results then compared to Ansys Maxwell FEA simulation results from $100 \mathrm{KHz}$ to $10 \mathrm{MHz}$. A summary of series inductance and equivalent series resistance is shown in figure 7 . The results show good matching between the simulation results and measurements.

The inductor was connected to the test buck converter. The measured efficiency versus output current of the converter at three different input voltages and a fixed output voltage is shown in figure 8 . The converter has maximum efficiency of
$84.7 \%$ at $12 \mathrm{~V}$ input voltage and $78 \%$ at $24 \mathrm{~V}$ input voltage. The total converter power loss is also shown in figure 9.

Based on the inductor characterization, the $\mathrm{AC}$ resistance at $10 \mathrm{MHz}$ is $426 \mathrm{~m} \Omega$. Combining the $\mathrm{DC}$ and $\mathrm{AC}$ losses of the inductor, the total loss of the inductor is calculated and plotted versus the load current in figure 10.

\section{CONCLUSION}

In this paper, a two layer printed circuit board circular spiral inductor was experimented for a $5 \mathrm{~W}$ buck converter. Finite elements analysis for the inductor was carried out and the simulation results show good match to the measured inductance and the equivalent series resistance. The inductor was tested successfully in a buck converter circuit. The converter achieved $84.7 \%$ peak efficiency running at $10 \mathrm{MHz}$. the power stage was designed using gallium nitride power FETs and the gate driver signals were supplied from a dead time adjustment circuit.
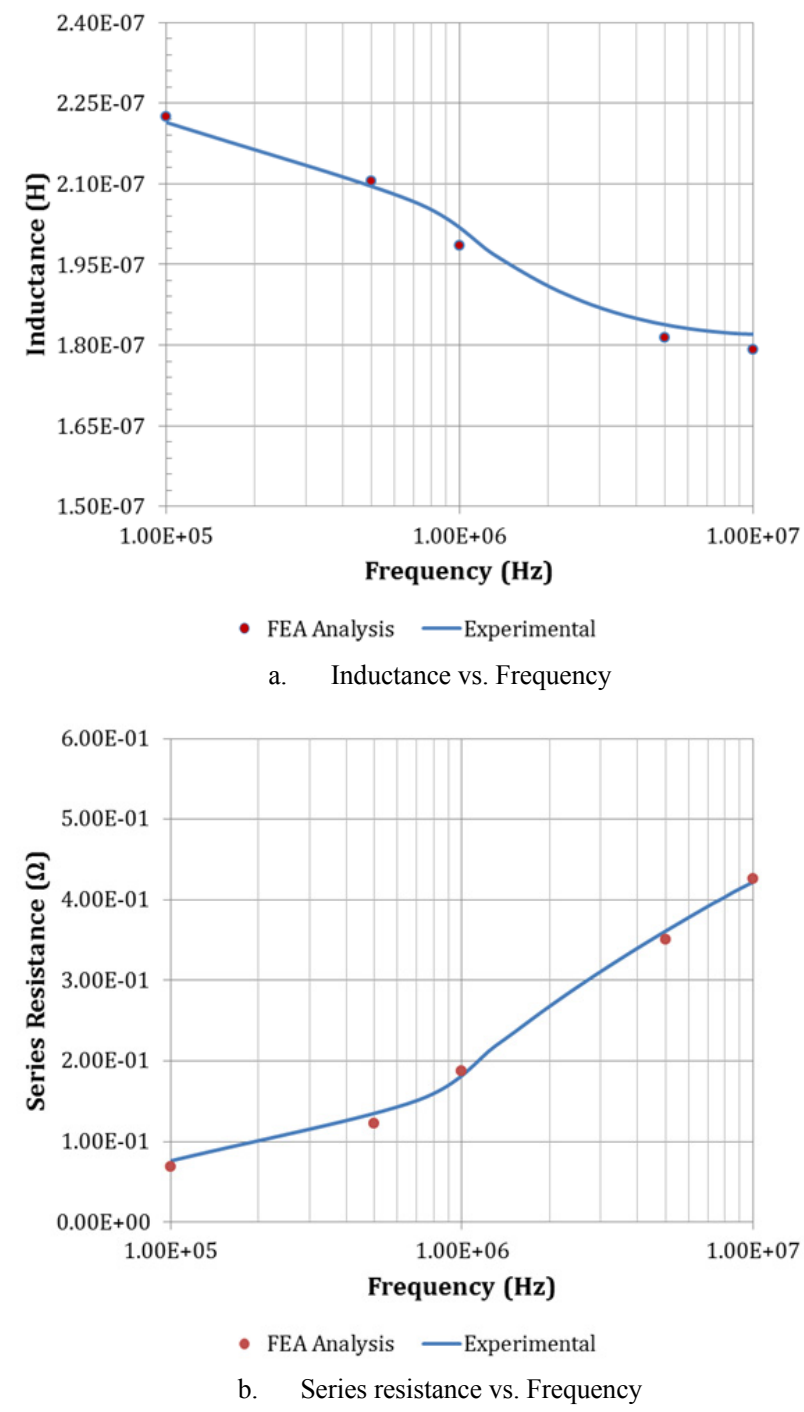

Fig.7. Ring spiral inductor FEA simulation results and Lab measurements 


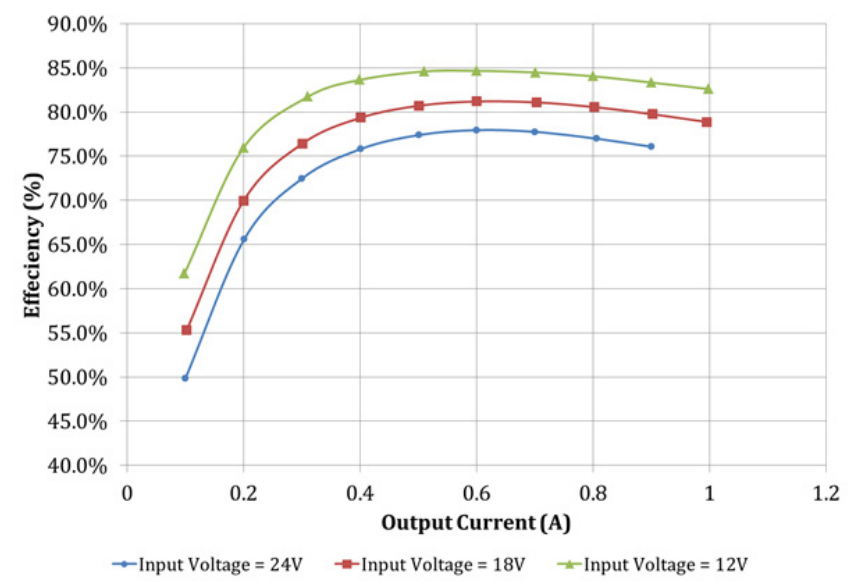

Fig.8. Efficiency vs. Output Current of the test converter at 5 V output voltage

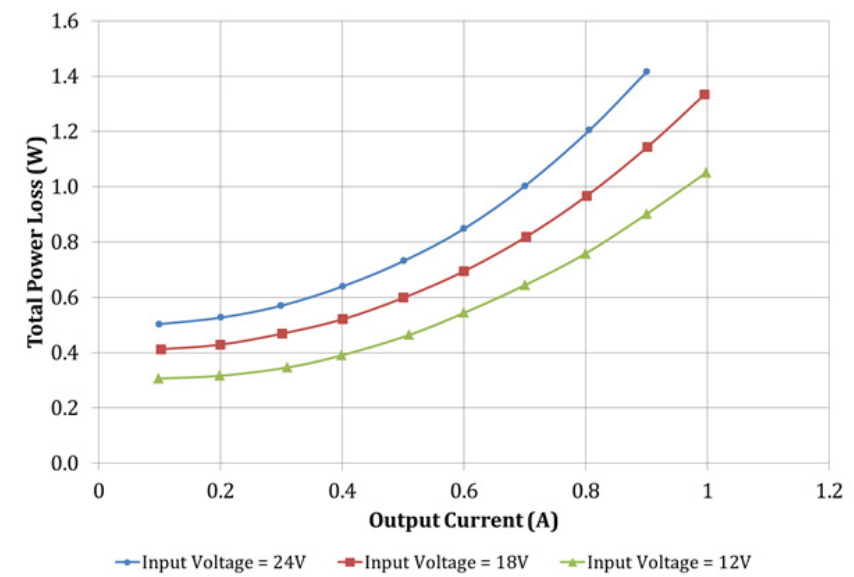

Fig.9. Total Power Loss vs. Output Current of the test converter at 5 V output voltage

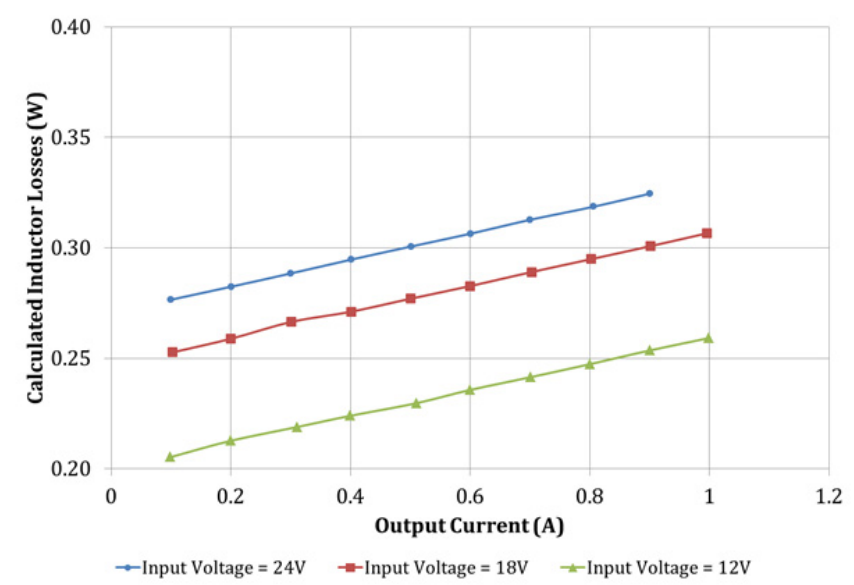

Fig.10. Total Inductor Power Loss vs. Output Current of the test converter at 5 V output voltage

\section{REFERENCES}

[1] Yasser Nour, Arnold Knott, Ivan H. H. Jørgensen, "Investigating Enhancement Mode Gallium Nitride Power FETs in High Voltage, High Frequency Soft Switching Converters," in IEEE International Conference on Power electronics, machines and drives (PEMD 2016), Glasgow, 2016.

[2] W. Lee, D. Han, C. Morris and B. Sarlioglu, "Minimizing Switching Losses in High Switching Frequency GaN-based Synchronous Buck Converter with Zero-Voltage Resonant-Transition Switching," in 9th International Conference on Power Electronics and ECCE Asia (ICPEECCE Asia), Seoul, 2015

[3] D. Hui, Y. Zhu and B. Zhao, "Calculation and Application in RFID of the PCB Spiral Inductors," in IEEE International Conference e-Business Engineering (ICEBE '09), Macau, 2009.

[4] P. Kamby, A. Knott and M. A. E. Andersen, "Printed circuit board integrated toroidal radio frequency inductors," in 38th Annual Conference on IEEE Industrial Electronics Society (IECON 2012), Montreal, QC, 2012.

[5] J. D. Mønster, M. P. Madsen, J. A. Pedersen and A. Knott, "Investigation, development and verification of printed circuit board embedded air-core solenoid transformers," in IEEE Applied Power Electronics Conference and Exposition (APEC 2015), Charlotte, NC, 2015.

[6] J. Pejtersen and A. Knott, "Design and measurement of planar toroidal transformers for very high frequency power applications," in 7th International Power Electronics and Motion Control Conference (IPEMC 2012), Harbin, China, 2012.

[7] C. O. Mathuna, N. Wang, S. Kulkarni and S. Roy, "Review of integrated magnetics for power supply on chip (PwrSoC)," IEEE Trans. on Power Electronics, vol. 27, no. 11, pp. 4799-4816, Nov. 2012.

[8] Z. Ouyang and M. A. E. Andersen, "Overview of planar magnetic technology-fundamental properties," IEEE Transactions on Power Electronics, vol. 29, no. 9, pp. 4888-4900, Sept. 2014.

[9] W. B. Kuhn, et al, "Analysis of crowding effects in multiturn spiral inductors," IEEE Trans. on Microwave Theory and Techniques, vol. 49, no. 1, pp. 31-37, Jan. 2001.

[10] B. L. Ooi, et al, "Modified inductance calculation with current redistribution in spiral inductors," IEE Proceedings on Microwaves, Antennas and Propagation, vol. 150, no. 6, pp. 445-450, Dec. 2003.

[11] W. G. Hurley and M. C. Duffy, "Calculation of self- and mutual impedances in planar sandwich inductors," IEEE Trans. on Magnetics, vol. 33, no. 3, pp. 2282-2290, May. 1997.

[12] S. Chen, O. Trescases and W. T. Ng, "Fast Dead-Time Locked Loops for a high-efficiency microprocessor load ZVS-QSW DC/DC converter," in IEEE International Conference on Electron Devices and Solid-State Circuits, 2003.

[13] M. Rodriguez, Y. Zhang and D. Maksimovic, "High-Frequency PWM Buck Converters Using GaN-on-SiC HEMTs," IEEE Transactions on Power Electronics, vol. 29, no. 5, pp. 2462 - 2473, 2014.

[14] Yasser Nour, "CMOS Realization of High Switching Frequency Integrated Buck Converter," M.Sc. Thesis, South Valley University, Aswan, Egypt, 2011.

[15] Yasser Nour, Mohamed Orabi and Ashraf Lotfi, "High frequency QSWZVS integrated buck converter utilizing an air-core inductor," in Applied Power Electronics Conference and Exposition (APEC), 2012.

[16] Corporation, Efficient Power Convertion, "EPC8010 - Enhancement Mode Power Transistor Datasheet," 2015.

[17] W. G. Hurley and M. C. Duffy, "Calculation of self and mutual impedances in planar magnetic structures," IEEE Transactions on Magnetics, vol. 31, no. 4, pp. 2416-2422, July 1995. 